FERMIIAB-TM-1832

\title{
Overview of a Robotic System for Azimuthal Dimensions of SSC Dipole Coils
}

D.L. Assell, J.M. Cahill, J.A. Carson, D.F. Connolly, S.K. Pawlak, R.K. Rihel, W.R. Robatzek, W.F. Robotham, E. Schmitz, R. Sims, T.M. Skweres and R. Ullmark

Fermi National Accelerator Laboratory

P.O. Box 500, Batavia, Illinois 60510

March 1993 


\section{Disclaimer}

This report was prepared as an account of work sponsored by an agency of the United States Government. Neither the United States Government nor any agency thereof, nor any of their employees, makes any warranty, express or implied, or assumes any legal liability or responsibility for the accuracy, completeness, or usefulness of any information, apparatus, product, or process disclosed, or represents that its use would not infringe privately owned rights. Reference herein to any specific commercial product, process, or service by trade name, trademark, manufacturer, or otherwise, does not necessarily constitute or imply its endorsement, recommendation, or favoring by the United States Government or any agency thereof. The views and opinions of authors expressed herein do not necessarily state or reflect those of the United States Government or any agency thereof. 


\title{
OVERVIEW OF A ROBOTIC SYSTEM
}

\section{FOR AZIMUTHAL DIMENSIONS OF SSC DIPOLE COILS}

\author{
D.L. Assell, ${ }^{1}$ J.M. Cahill, ${ }^{1}$ J.A. Carson, ${ }^{1}$ D.F. Connolly, ${ }^{1}$ S.K. Pawlak, ${ }^{1}$ \\ R.K. Rihel, ${ }^{1}$ W.R. Robatzek, ${ }^{1}$ W.F. Robotham, ${ }^{1}$ E. Schmitz, ${ }^{2}$ R. Sims, ${ }^{2}$ \\ T.M. Skweres, ${ }^{1}$ R. Ullmark, ${ }^{2}$
}

${ }^{1}$ Fermi National Accelerator Laboratory, P.O. Box 500, Batavia, Ill. 60510

2 Superconducting Super Collider Laboratory, Fermilab/SSC Magnet Project,

P.O. Box 500, Batavia, Ill. 60510

\begin{abstract}
This system measures the azimuthal dimensions of SSC dipole long coils automatically, taking over 500 measurements in less than four hours. These measurements are then analyzed and displayed via software reports which reveal coil statistics, point by point dimensional graphics, modulus of elasticity measurements, comparisons with previous coils and pre-collaring shimming information. The rapid turnaround of this system yields the ability to spot process variables and fine tune the fabrication techniques. This process will aid in producing coils to the required precision.
\end{abstract}

\section{INTRODUCTION}

The SSC will require the production of approximately 8,000 dipole magnets. Each dipole will require two inner and two outer coils. This will require the production of approximately 32,000 coils, each 15 meters in length. To assess the quality of the coils during the manufacturing process a measuring system is needed. Fermilab has developed a coil measuring machine as part of its prototype manufacturing facilities (see Figure 1).

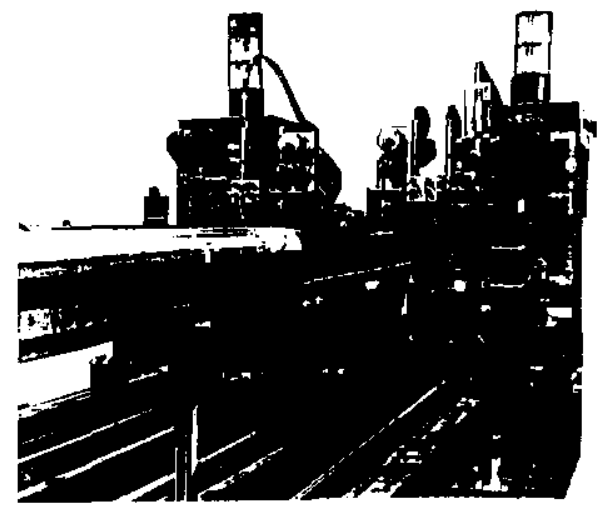

Figure 1. Coil Measuring Machine 
Coil measurements are made by confining the coil in a fixture which replicates the collared geometry of the coil (see figure 2). The coil is then compressed by applying a known pressure at the parting plane. Coil displacement is noted and compared to measurements made of a precision steel block fabricated to the nominal collared coil dimensions.

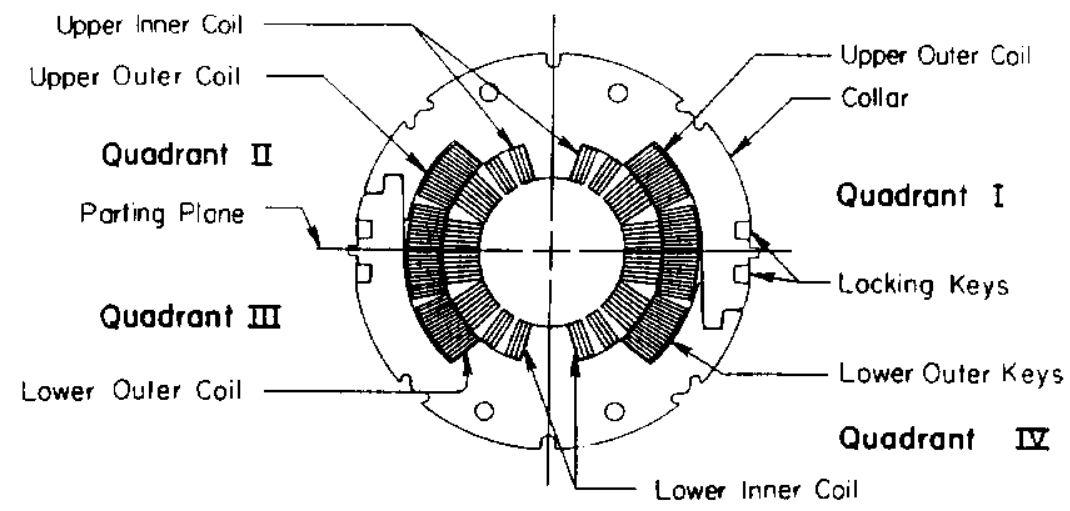

Figure 2. Collared Coil Assembly

The measuring process is done at $7.62 \times 10^{-2} \mathrm{~m}$ increments along the entire length of the coil. The pressure applied to the coil during the measuring process, $82.74 \mathrm{mPa}$, is consistent with the prestress the coils will see when collared.

In addition, at every 20 th increment or 1.52 meters, coil measurements are made at $41.37 \mathrm{mPa}, 55.16 \mathrm{mPa}$ and $68.95 \mathrm{mPa}$. These additional measurements are used to calculate the modulus of elasticity for the coil. As the measurement process is being conducted the coil resistance is also monitored for turn to turn shorts which are most likely to occur when the coil is under pressure. This resistance monitoring affords an opportunity to find shorts and repair before the coils are assembled.

The machine developed at FNAL to accomplish these measurements consists of the following systems.

1) Linear motion system

2) Mandrel support system

3) Measuring head system

4) Control and data acquisition system

5) Safety system

These systems are controlled and operated by a computer, making the machine completely automated. This automation allows the taking of over 500 data points in less than four hours.

\section{OPERATION}

A coil is placed on the measuring machine mandrel. After assuring the coil is properly positioned the operator starts the machine. The operator is prompted to enter pertinent coil information. With all prompts satisfied, the measurement sequence begins. All machine functions are now directed by the computer. The operator is signaled when the process is complete, if a machine malfunction occurs or if a coil short is sensed.

Before loading the coil the measuring head is in a parked position at the extreme end of the support mandrel (see Figure 3). The park position is where the calibration master standards are located. The measurement process starts with the calibration of the measuring head. The measuring head consists of a precision cavity which matches exactly the nominal coil outer radius and coil pole. Pressure bars define the parting plan. The bars, one for each side of the coil, bear against the coil parting plane. Force is applied to the bars via hydraulic jacks. Each bar is made of 3 pieces. The hydraulic force is applied uniformly to each of the 3 pieces. The purpose here is to eliminate end effects. Vertical displacement of the center bar piece is measured by a linear motion probe (see Figures 4 and 5). 

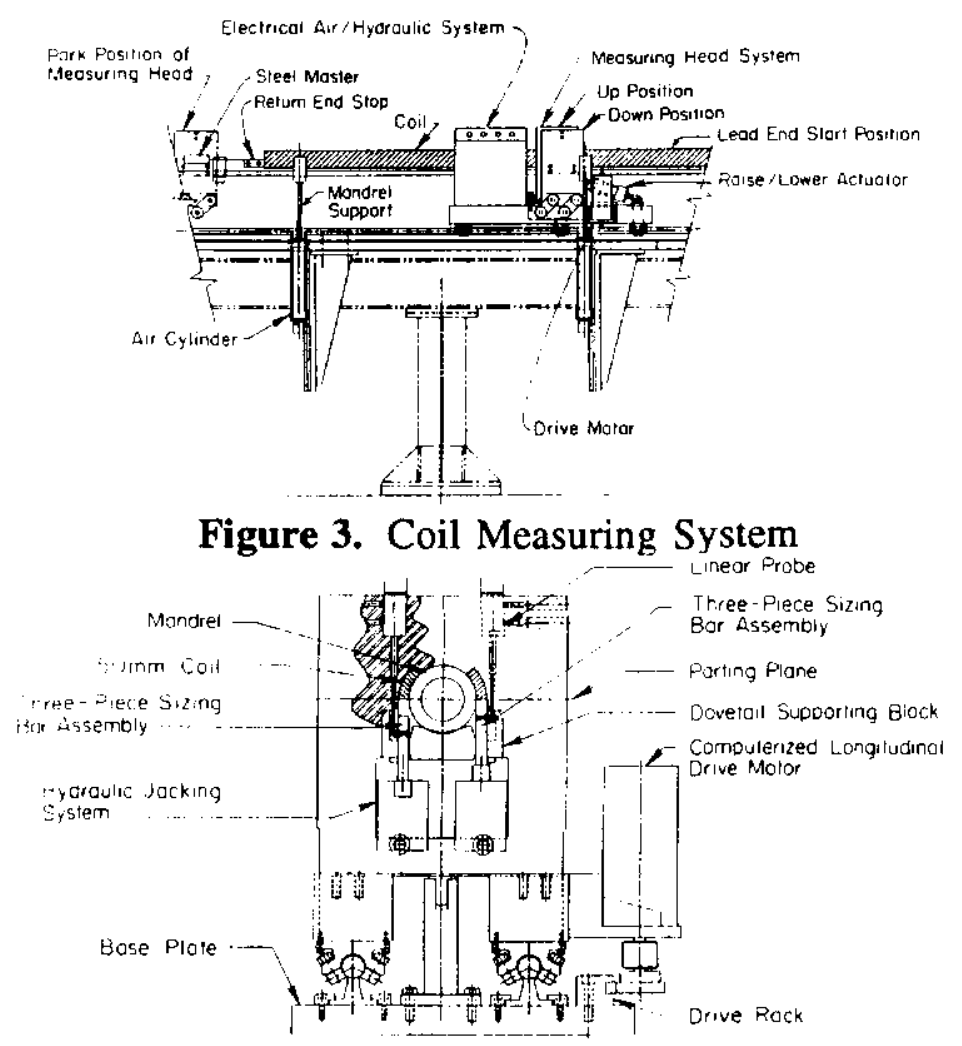

Figure 4. $50 \mathrm{~mm}$ Coil Measuring Head

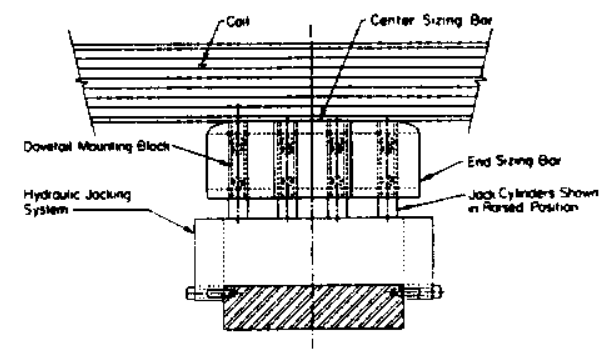

Figure 5. Three Piece Pressure Bar Assembly

Calibration is accomplished by lowering the head onto the calibration standards or blocks. Hydraulic force is applied to achieve $41.37 \mathrm{mPa}, 55.15 \mathrm{mPa}, 68.95 \mathrm{mPa}$, and $82.74 \mathrm{mPa}$ pressure on the blocks. At $41.37 \mathrm{mPa}$ the measurement probe is zeroed. All subsequent measurements of the calibration standards and coil are relative to this zero. The calibration will be checked again at the end of the coil measurement sequence to ascertain that no substantial drift of the calibration has occurred.

Once the calibration is complete the measuring head is raised and moved to the first coil measurement position. The coil is measured when compressed to $82.74 \mathrm{mPa}$. The pressure is held for a preset interval to allow for coil stress relaxation to occur. The process is repeated until the entire coil is measured. As the measuring head moves down the mandrel, the mandrel supports are lowered to allow the head to pass (see Figure 6). The longest span of unsupported mandrel is 1.22 meters. The stiffness of the mandrel provides negligible deflection.

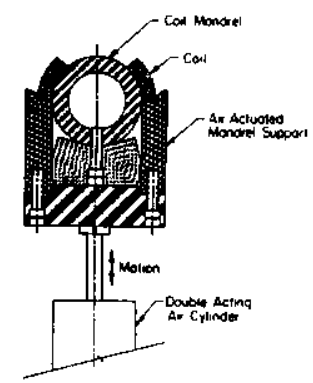

Figure 6. Coil and Mandrel 
Coil Width

$50 \mathrm{~mm}$ Inner $1.267 \times 10^{-2} \mathrm{~m}$

$50 \mathrm{~mm}$ Outer $1.217 \times 10^{-2} \mathrm{~m}$

Effective Hydraulic Cylinder Area

$2.477 \times 10^{-3} \mathrm{~m}^{2}$

Calculations

$55.16 \mathrm{mPa}$ coil probe reading minus $55.16 \mathrm{mPa}$ master probe reading

$82.74 \mathrm{mPa}$ coil probe reading minus $82.74 \mathrm{mPa}$ master probe reading

Pump Pressures on the Block

Pump mPa $=$ (Block Pressure)(Coil Area)

(Hydraulic Cylinder Area)

Modulus of Elasticity between $55.16 \mathrm{mPa}$ and $82.74 \mathrm{mPa}$

$\mathrm{E}=\frac{\text { Stress }}{\text { Strain }}=\frac{\mathrm{P} / \mathrm{A}}{\Delta \mathrm{L} / \mathrm{L}}$

$\mathrm{P} / \mathrm{A}=82.74 \mathrm{mPa}-55.16 \mathrm{mPa}=27.58 \mathrm{mPa}$

$\mathrm{L}=$ Master length plus or minus the coil deviation with respect to the master.

$\Delta \mathrm{L}=$ Coil size with respect to master at $55.16 \mathrm{mPa}$ minus coil size with respect to master at $82.74 \mathrm{mPa}$.

The collected data is post processed from a floppy disk using EXCEL ${ }^{(\mathcal{C}}$. Figure 7 shows a sample data sheet produced by the program for one coil. The program prints average coil size, standard deviation, range of coil size, smallest and largest reading and modulus of elasticity for each quadrant. Figure 8 shows a sample graph of quadrants I/III and II/IV representing measurements taken on both sides of a coil plotted for all 190 positions. Various other graphs are plotted to characterize coil features and help to analyze causes of variations. Figure 9 shows the whole coil average for 3 different coils. It is apparent that the variations are systematic, probably caused by tooling variations.

\section{CONTROL SYSTEM}

The control system program, run by a 386 computer with an $80 \mathrm{MB}$ hard drive, is written in ASSYST. The subprograms necessary to safely accomplish the accurate measurement of an SSC magnet coil can be broken down into the following subsystems (see Figure 10).

1) Linear motion system

2) Mandrel support system

3) Measuring head system

4) Sizing and data system

5) Safety system

\section{LINEAR MOTION SYSTEM}

The linear motion necessary to accurately position the head at 190 predetermined points is accomplished with an encoder, decoder, stepper motor and indexer drive. These are linked to the host computer via an RS-232 port. The encoder, which is always used, knows its absolute position, even if power is lost. The indexer and motor drive are powered by an isolation transformer to further minimize errors due to noise. This has given the system high accuracy and repeatability. When a move command is issued by the computer, the indexer will step the motor drive until the encoder tells the computer that the desired position has been achieved. 


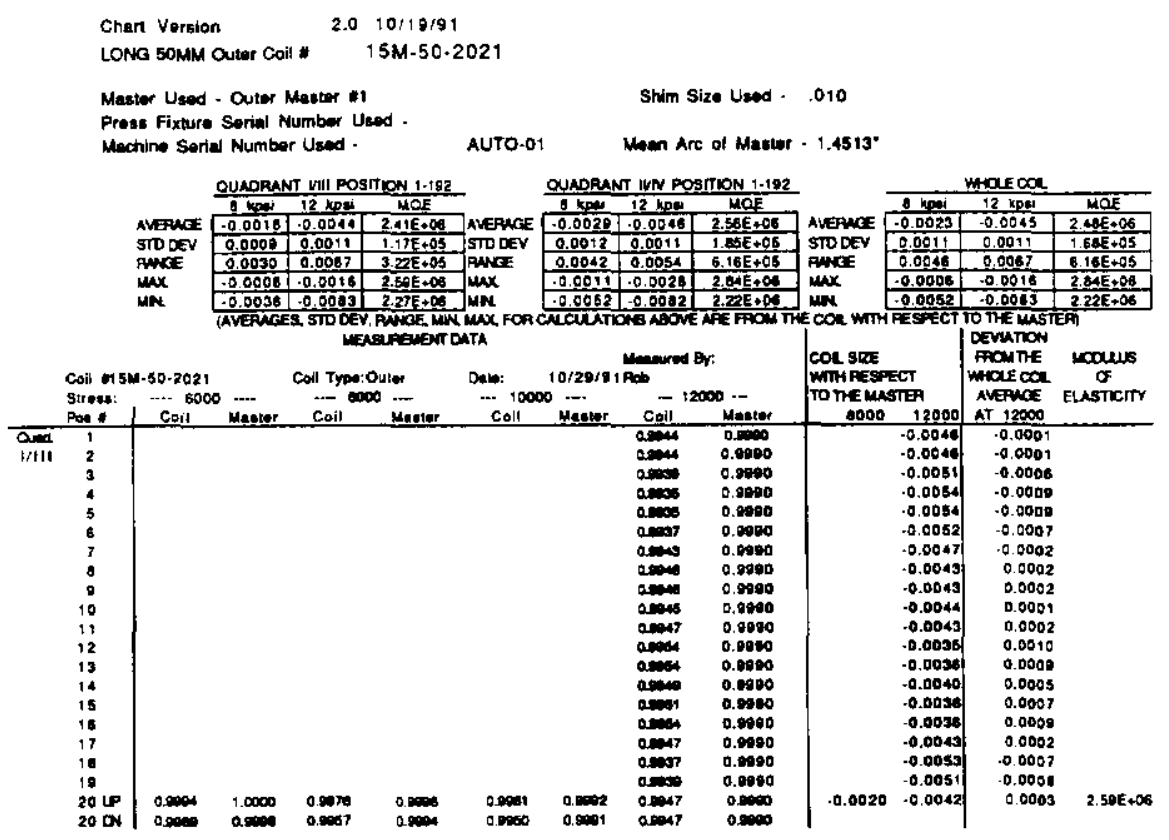

Figure 7. Sample Data Sheet
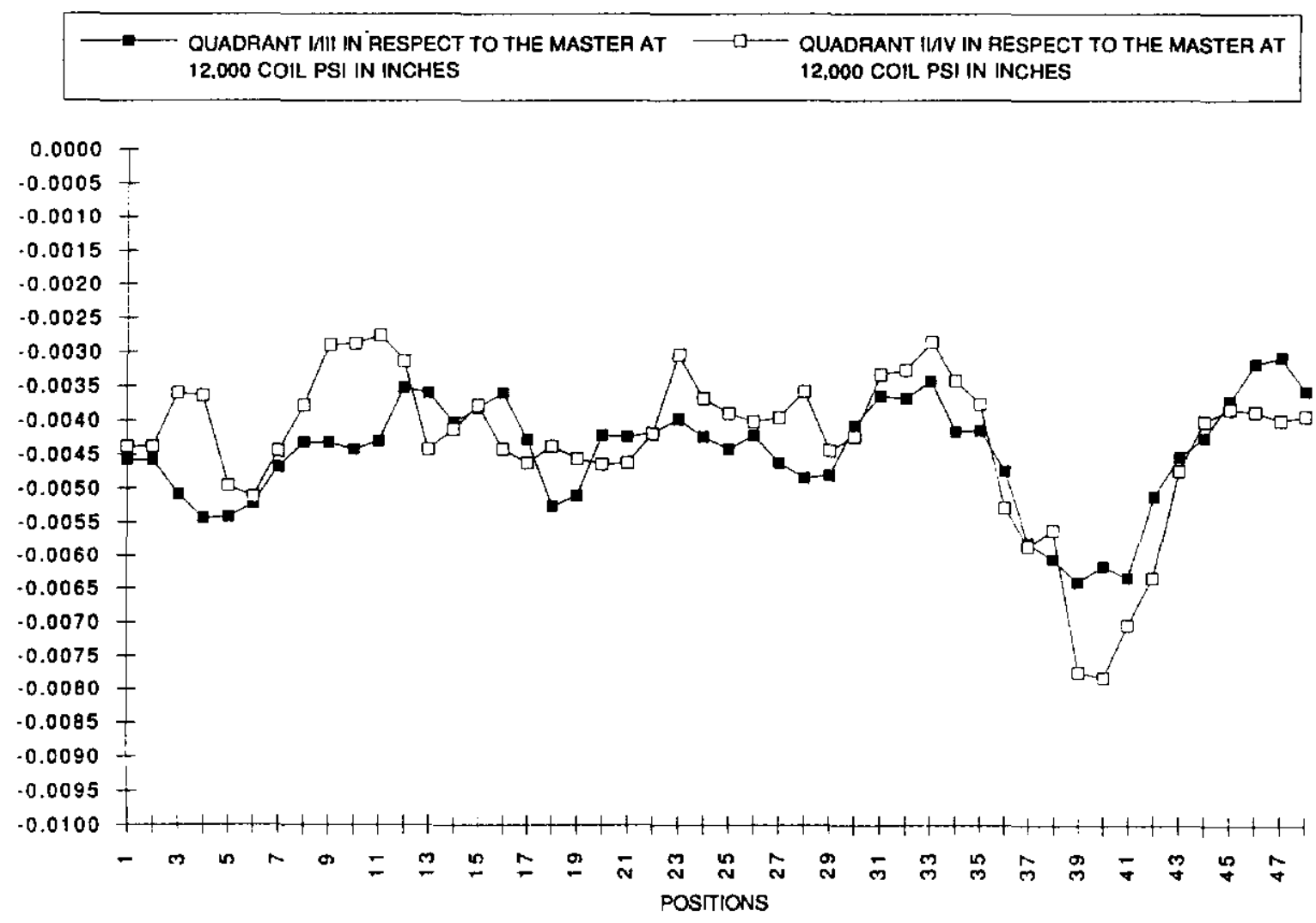

Figure 8. Sample Graph of Quadrants I/III and II/IV 


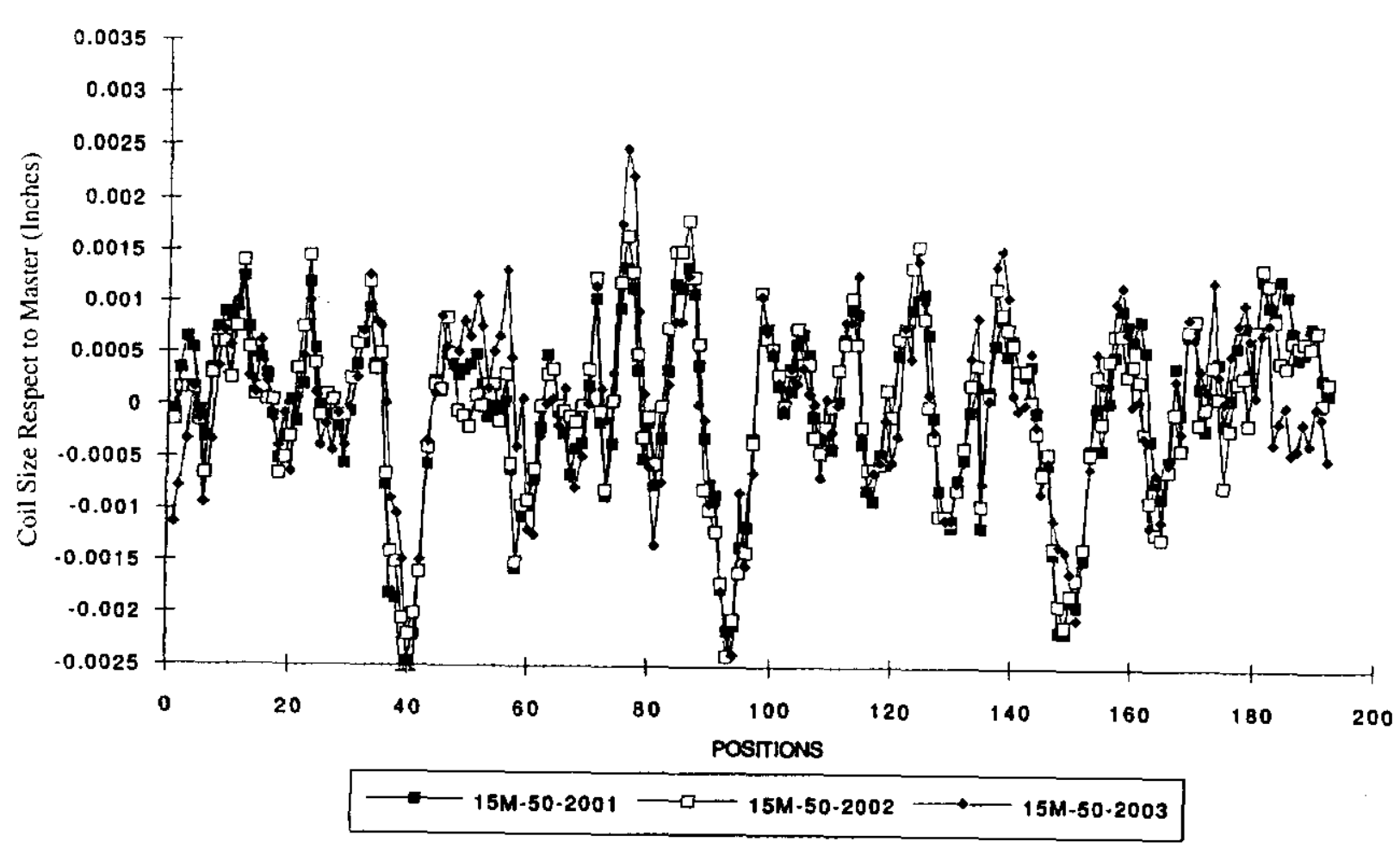

Figure 9. Whole Coil Average for 3 Different Coils

\section{MANDREL SUPPORT SYSTEM}

There are fourteen legs to support the mandrel and coil during the measuring process. The legs are attached to air driven cylinders that allow them to be raised and lowered independently, clearing a path for the measuring head. The air cylinders are controlled by solenoids activated by the computer through a 24 -channel digital I/O card and a 24-channel relay card. The host computer is informed of the measuring head location by the encoder, then raises and lowers the mandrel support legs at predetermined positions. In the manual mode the mandrel legs must be actuated locally.

\section{MEASURING HEAD SYSTEM}

The measuring head system can be broken down into two complementing operations: raising and lowering the measuring head and actuating the pressure bars.

The measuring head is raised and lowered by air driven cylinders. The host computer activates a solid state relay (SSR) with a digital I/O channel that energizes a three way solenoid valve to deliver house air to the cylinders. The computer also detects the head position with microswitches. Linear motion is inhibited unless the head-up switch is engaged and sizing bar cylinders are also inhibited unless the head-down switch is engaged.

The coil is measured at four stress values: $41.37 \mathrm{mPa}, 55.16 \mathrm{mPa}, 68.95 \mathrm{mPa}$ and $82.74 \mathrm{mPa}$. The pressure bars are raised by eight hydraulic cylinders. The hydraulic fluid is supplied by a Haskel air over oil pump with a 75:1 amplification ratio. The air pressure to the pump is controlled by a Fairchild transducer, which is programmed by the computer through a digital-to-analog channel. The pump is equipped with a fast fill feature. This consists of a buffer tank that contains hydraulic fluid and is topped off with an air head.

In fast fill mode an SSR activates a three way solenoid to apply house air pressure to the top of the buffer tank. This supplies the coil sizing cylinders with a larger volume of fluid, by forcing oil through the easy direction of the two one-way valves in the pump. When the coil compression cylinders meet resistance by each pressing lightly on the coil body, the pump takes over and raises the pressure to the programmed value. The coil compression cylinders are retracted using an accumulator. The front end of the 


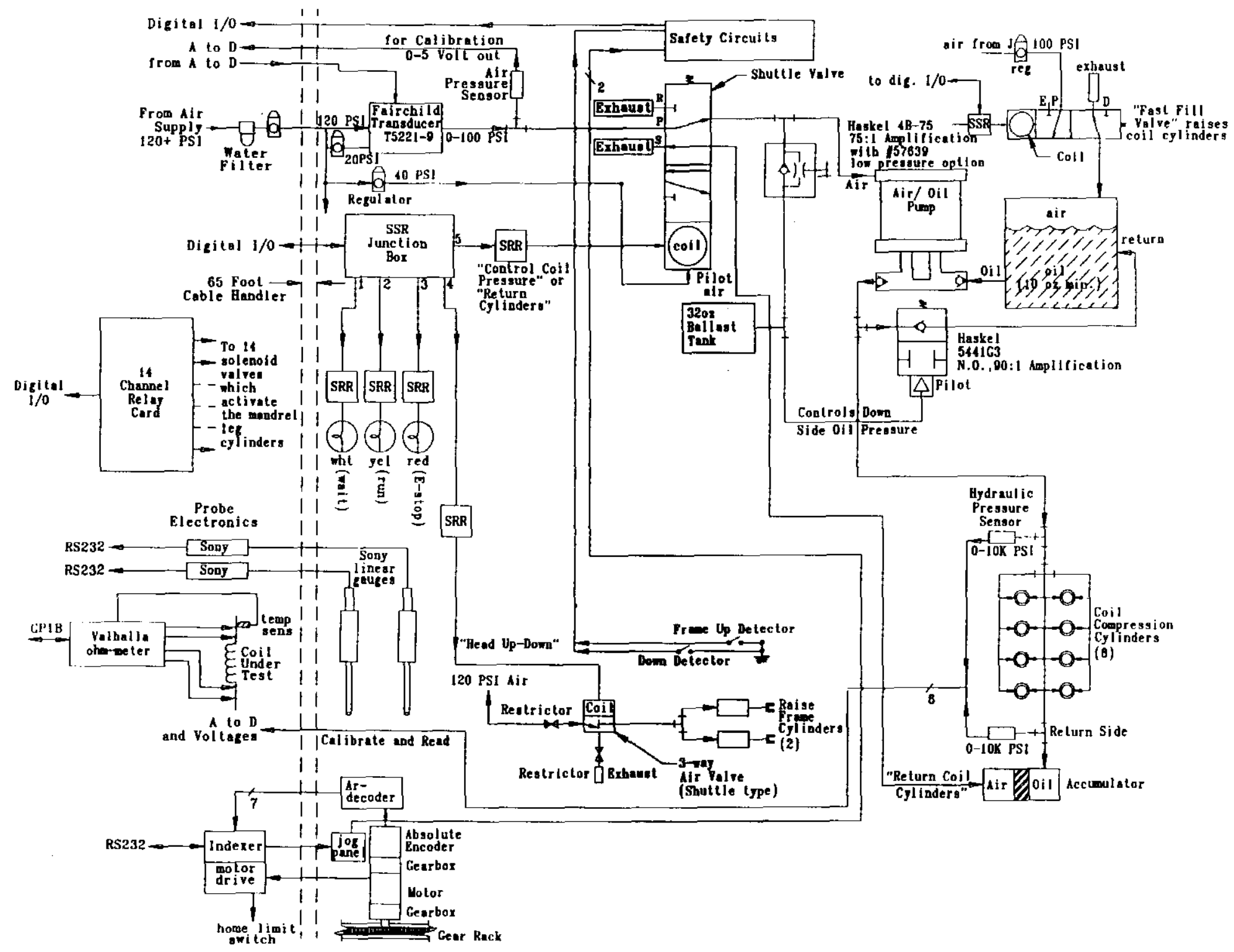

Figure 10. Automatic Measuring System Controls 
accumulator sees house air when activated by a solenoid. The back side of the accumulator is oil filled and attached to the return side of the compression cylinders. All pressures are regulated using feedback supplied by Sensotech pressure transducers.

\section{SIZING AND DATA SYSTEM}

All data relating to azimuthal size is taken using Sony linear probes. These are read back by the computer at the designated stress values with an RS-232 link. Thermocouples are used to measure the temperature of the measuring head and are read with $A / D$ channels. The coil resistance is monitored during the sizing operation by the Valhalla Micro-ohm meter with GPIB interface. The coil temperature is measured by an aluminum half cylinder under the coil and is fed to the Micro-ohm meter for the correction of the reading.

\section{SAFETY SYSTEM}

The safety system includes the raise and lower head detector microswitches already mentioned and a pressure bar up detector which also uses a microswitch. There are bumpers installed in front and back of the measuring head. If an obstruction is detected in the path of the head, a microswitch is activated by the bumpers and all operations are halted. There is also an emergency stop pushbutton located on the front panel of the control box on the measuring head. This will also halt all operations when depressed.

\section{CONCLUSION}

The automatic coil measuring system provides constant monitoring of the azimuthal coil size for both the inner and outer coils. This information is a valuable asset in the production of uniform coils. It can alert one to the possibility of tooling problems during cabling, winding or curing as well as assembly and testing. This system provides complete data on every coil that goes into the making of uniform SSC dipoles. 